\title{
On the Threshold of a New Medicine
}

\begin{tabular}{|l|l|l} 
P.M. & Schlag \\
\hline
\end{tabular}

The scientific objectives with regard to etiopathology and diagnosis of malignant tumors have fundamentally changed in the last years by the introduction and refining of molecular techniques and approaches. For the first time hopes are cherished that the causes, risks and the correlation between carcino-genesis and metastatic spread will soon be understood and not merely phenomenologically described as in the past. The next step, the development of specific therapeutic strategies based on this knowledge, which will be much more effective as the currently available ones because of their higher specification and selectivity, thus seems to get closer. Although it is not yet foreseeable that these new strategies will generally replace the present standard therapies (surgery, radio- and chemotherapy), first signs of changed diagnosis in primary and secondary therapy of malignant tumors are emerging. New methods of tumorpreventive treatment, based on genetic risk analysis of cancer, might also be applied. Here new ground in diagnosis and therapy is broken, which raises new questions and problems - not only methodological, but also psychosocial and ethical ones. In the future the task will be to develop, in the interest of the sick and the healthy, effective and tolerable strategies, which will help to appropriately use the available and future potential of this medical evolution; furthermore, the attention should not only be directed to molecular biology, but also to the further development of other possibilities of diagnosis and therapy of malignant tumors. In this issue of 'ONKOLOGIE' the reader shall be informed in various papers about the state of the art of molecular biologic and genetic examinations of gastrointestinal tumors. Of course, these selected articles may only serve as an lead-in to this complex and rapidly growing field. Its correct transformation, taking into account the above-mentioned problems, requires a competent information of all persons involved in the treatment of tumor patients. This issue of

'ONKOLOGIE' is aimed to make a contribution to this topic, encouraging a further discussion.

\section{KAIVGER}

(C) 1997 S. Karger GmbH, Freiburg Fax (0761) 4520714 http://www.karger.ch

Prof. Dr. med. Peter M. Schlag Virchow-Klinikum, Medizinische Fakultät der HumboldtUniversität zu Berlin, Robert-Rössle-Klinik Abteilung für Chirurgie und Chirurgische Onkologie Lindenberger Weg 80, D-13125 Berlin (Germany) 